\title{
PRACTICAL GUIDELINES FOR ASSESSING CORAL CALCIFICATION VIA COMPUTED TOMOGRAPHY
}

\author{
Intan Suci Nurhati* \\ Research Center for Oceanography. Indonesian Institute of Sciences (LIPI). Jakarta, Indonesia. \\ *Correspondence author: <inta007@lipi.go.id>
}

Received: December 2018 Accepted: December 2018

\begin{abstract}
Coral calcification as the product of extension rate and skeletal density, is projected to change under marine environmental changes of local (e.g., sedimentation, eutrophication) and global (e.g., warming, ocean acidification) scales. For the regional effort to monitor the ecological impacts of ocean acidification on coral reef ecosystems, the Intergovernmental Oceanographic Commission Sub-Commission for the Western Pacific (IOC-WESTPAC) has incorporated an interdisciplinary approach that includes monitoring of seawater carbonate parameters, coral calcification, net calcification minus bioerosion, and reef community structure. Currently, there is a need to formulate a standard operating procedure (SOP) for assessing coral calcification over the recent years via coral cores. The SOP needs to yield accurate data in a cost-effective way that can be applied by researchers in the region. High variation of coral calcification parameters between coral colonies warrants a sufficiently large number of samples thus a rapid method for analyzing coral extension rate, skeletal density, and calcification. This paper outlines practical guidelines for assessing coral calcification from the field to laboratory using the threedimensional computed tomography (CT) method.
\end{abstract}

Keywords: coral calcification, extension rate, skeletal density, CT scan, IOC-WESTPAC.

\section{INTRODUCTION}

Coral calcification, the process in which reefbuilding corals build their skeletons by secreting layers of aragonite during their lifetime, may change under anthropogenic pressures. On a global scale, the Intergovernmental Panel on Climate Change (IPCC) has projected a decline in coral calcification rate under the ongoing ocean warming and acidification trends as slow onset changes occurring in the oceans (Wong et al., 2014). However, field observations and tank experiments have illustrated complex responses of coral calcification to environmental physicochemical parameters such as temperature and pH (Lough and Cooper, 2011; and references therein).
The United Nations' Sustainable Development Goals (SDGs) has set the target to "minimize and address the impacts of ocean acidification, including through enhanced scientific cooperation at all levels" as part of SDG 14 - Life below water. The Intergovernmental Oceanographic Commission Sub-Commission for the Western Pacific (IOC-WESTPAC) has initiated a regional effort to monitor the ecological impacts of ocean acidification on coral reef ecosystems in 2014. The regional effort becomes imperative considering that the western Pacific region is home to the wealthiest coral biodiversity in our planet: "The Western Pacific and its adjacent regions are among the richest and most productive in the world as they are home to more than 600 coral species 
(more than $75 \%$ of all known coral species) and $\sim 53 \%$ of the world's coral reefs... Despite the recognition that ocean acidification poses a great threat to ocean-based food security, the awareness of its impacts has emerged only over the last decade, and the ecosystem responses to ocean acidification are poorly understood" (http:// iocwestpac.org/oa/870.html). The community considers the research capability of the member states to implement an interdisciplinary approach to monitor seawater carbonate parameters (e.g., $\mathrm{pH}$, total alkalinity, dissolved inorganic carbon, $\mathrm{pCO}_{2}$ ), and coral calcification via cores, net calcification-bioerosion using calcifying accretion units (CAUs) and bioerosion monitoring units (BMUs), and reef community structure using the autonomous reef monitoring structures (ARMS). Significant progress has been made over the past four years with a current need to formulate an SOP for assessing coral calcification to aid generating data from the region.

This paper provides practical guidelines in assessing coral calcification starting from sample retrieval via underwater coral coring in the field to laboratory analysis using CT scan, to initiate the development of SOP for assessing coral calcification in the WESTPAC community. With high variations in coral calcification parameters between coral colonies and locations, it is crucial to generating well-replicated records of coral calcification. The cost of conducting a CT scan is considerably higher than $\mathrm{x}$-ray; however, more cores can be analyzed in a single scan. Moreover, the three-dimensional CT scan method has the advantage of yielding more rapid measurements of replicated coral calcification records (Bosscher, 1993; Cantin et al., 2010) compared to the more commonly used two-dimensional x-radiography method. The later requires correcting for the heel effect as the intensity of $\mathrm{x}$-radiography varies with distance from the center of exposure. The CT scan method also eliminates the need to physically slab the cores that could add inaccuracies in taking measurements along the main growth axis. Measurements of coral calcification that takes into account both annual growth rate and skeletal density may also reduce any age-related effects on coral samples (Lough, 2008).

\section{SAMPLE RETRIEVAL VIA UNDERWATER CORAL DRILLING}

\section{Sample and Site Selection}

Massive coral colonies of abundant distribution (e.g., Porites, Faviids) are prime target samples. A large number of core samples (approximately $>15$; see Statistical Estimation below) is required for coral calcification study. Coral colonies with prominent fish scars and boring worms, complex growth forms (i.e., towards one horizontal direction instead of a uniform vertical direction) and whose surface are exposed during low tide should be avoided (Figure 1). It is advised to retrieve samples from depths deeper than 4 meters to minimize biological effects of a particular colony.

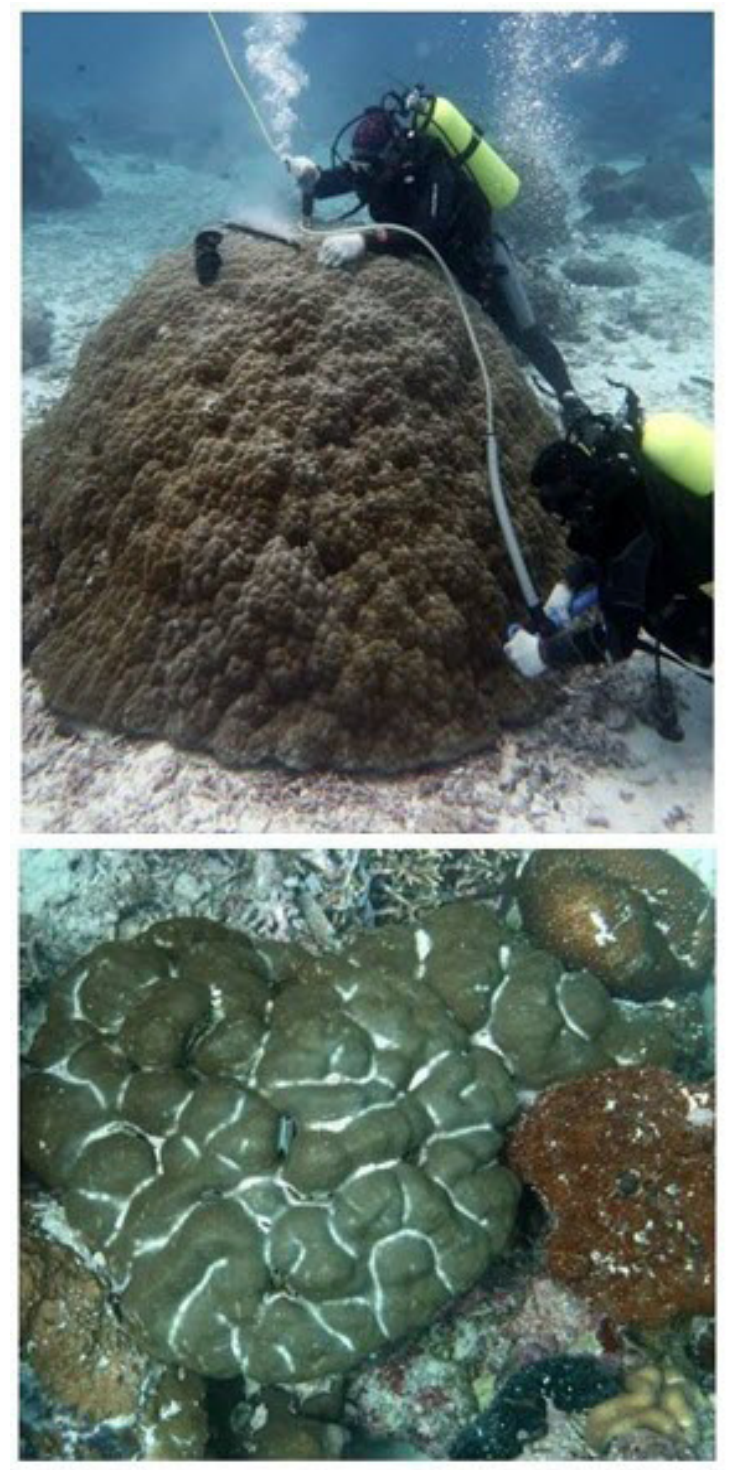

Figure 1. Suitable (top) and unsuitable (bottom) colonies Porites sp. coral for sampling. 
Coral colonies of Porites sp. tend to live together in a relatively low energy environment. During recce for potential coral colonies, it is recommended to conduct a manta tow where two snorkelers are slowly pulled by the boat in the direction perpendicular to the reef slope to make the process time-efficient. In some turbid places, however, this method is not applicable. For each sampled coral colony, take pictures of the colony underwater as well as note the GPS coordinates and the condition of the surrounding reefs that may influence coral calcification parameters such as current strength, turbidity, and proximity to human settlements.

\section{Coral Coring}

Coral core samples are retrieved using an underwater coral drill via SCUBA diving. The drill set consists of a rotating barrel with a diamond tip or other abrasive materials, a core breaker and a core catcher to enable drilling the core down the colony, and an optional water pump to flush seawater between the inner barrel and the coral to speed the process (Figure 2). Either pneumatic or hydraulic force can power the drill. The pneumatic drill is logistically more advantageous that fits into a check-in luggage (20-30 kg) and can be powered by a double piston gasoline-powered tire compressor available in small towns in the region. The hydraulic drill provides more power at the cost a bulkier cargo. The hydraulic oil can be substituted with biodegradable oil or in some models with seawater for a more environmentally friendly practice working in the reefs.

Retrieval of longer core pieces, as opposed to shorter cores, would help the subsequent steps in the laboratory. The coring process starts with holding the barrel against a peaked surface of the coral colony. Once the barrel goes deep into the colony, a core breaker that is a metal stick with a sharp edge is inserted between the core and the colony to detach the core with the push of a hammer. Subsequently, a coral catcher is used to grab the detached core. Coral catcher is a metal barrel with flexible metal pieces protruding towards the inner barrel when used to grab the core and relaxed to release the grabbed core. The process continues by attaching extension rods to the drilling barrel, core breaker, and catcher. Different designs for underwater coral drill may involve a slightly different process. The use of a lift bag is required for work safety with attached mesh bags for the metal tools and retrieved core samples.

\section{Sample Transport and Storage}

After core retrieval, some steps need to be taken to avoid mold growth during the transport. It is best to wash the core samples with seawater instead of freshwater if the samples have to be transported before they are thoroughly dried in the field. Wrapping each of individual core with food plastic wrap is helpful not only to avoid mold to grow but also to keep the core intact if it gets broken during transit. For packing, it is recommended to put a thick layer of blanket and stack the cores without having to wrap each of the core in a bubble wrap or a similar material.

With a growing core collection, it is important to catalog the samples with its metadata (Dassie et al., 2017). In the lab, core samples are cleaned with deionized water and air dried in a laminar flow bench before analysis and storage. Some laboratories opt to use an oven in drying the core samples.
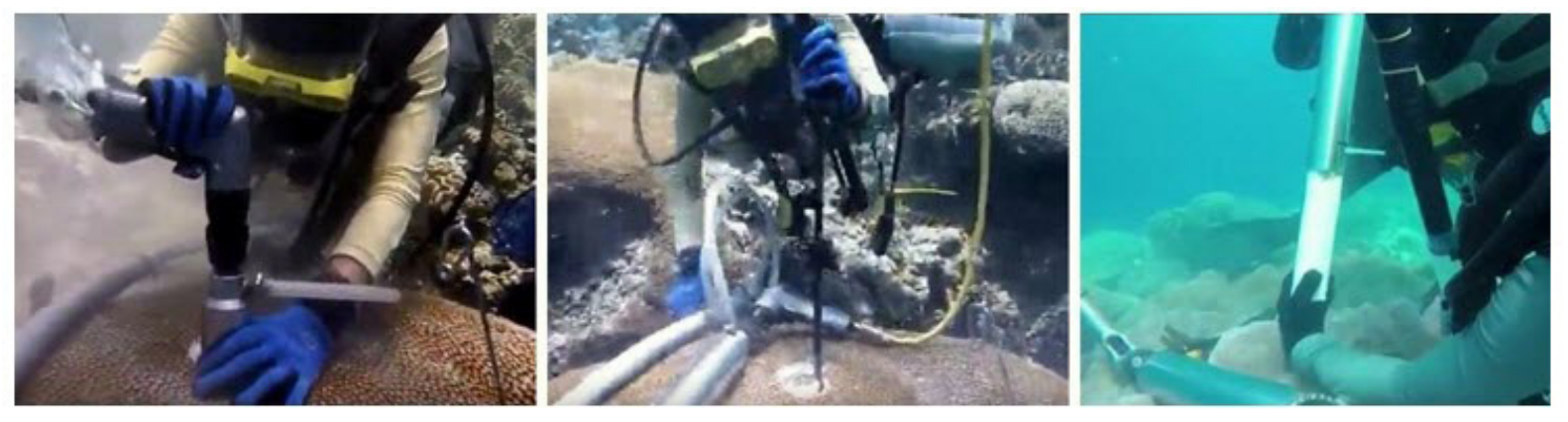

Figure 2. (Left) Coral drilling. (Center) Core breaker. (Right) Core catcher. 


\section{COMPUTED TOMOGRAPHY SCAN}

\section{CT Scanning}

Coral samples are analyzed with a CT scanner with a set of standards consisting of aluminum and aragonite standards at the beginning and end of the measurement (Figure 3). As a general guide, the CT scanner can be set with $300 \mathrm{mAS}$, $130 \mathrm{kV}$ and $0.6 \mathrm{~mm}$ slice during the analysis. The standards serve to calibrate coral skeletal density measurement from the Hounsfield $(\mathrm{Hu})$ unit used in the medical field to the SI unit for density $(\mathrm{g} /$ $\mathrm{cm}^{3}$ ). The aragonite standards are prepared from compressed homogenized material derived from Porites corals added with a small amount of cohesive material. Aluminum has a density of 2.70 $\mathrm{g} / \mathrm{cm}^{3}$, and the aragonite standards should have a density range that brackets a typical density of coral skeleton. Density values of the standards at the beginning versus the end of the measurement also could help to check for any drift during the scan.

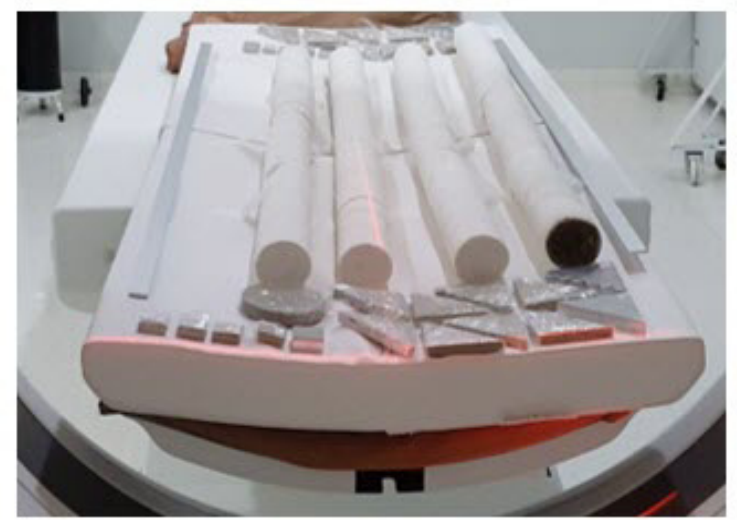

Figure 3. CT scan analysis with a set of standards consisting of an aluminum and aragonite standards at the beginning and end of each scan.

\section{Data Processing}

The CT scan result can be processed using a medical software such as OSIRIX $^{\circledR}$ by taking line measurements along major growth axes which yield the values for length and density (Figure 4). When moving from one transect to another, make sure to have overlapping measurements to avoid any trivial trend in the measurement. Coral extension rate is measured by taking the distance between each annual band, and skeletal density is converted to the density unit using the aluminum and coral standards. Coral calcification $\left(\mathrm{g} / \mathrm{cm}^{2}\right.$

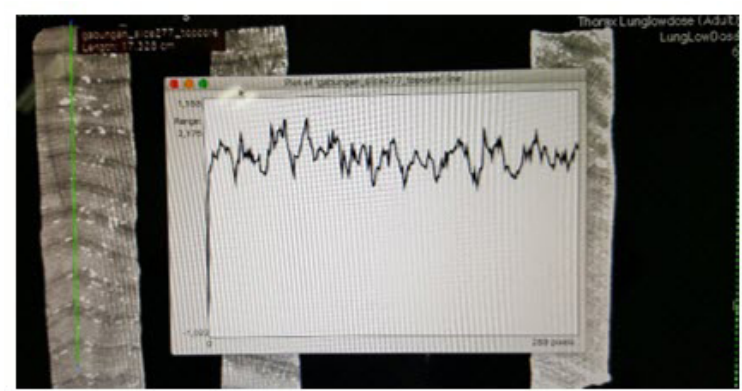

Figure 4. Retrieving density data along the core using OSIRIX $^{\circledR}$ software.

per year) is calculated as the product of linear extension rate $(\mathrm{cm} /$ year) and skeletal density $\left(\mathrm{g} / \mathrm{cm}^{3}\right)$. The measurements should be taken in replicates such as taking duplicate readings along front and side views. The method presented herein is a relatively simple method with a sufficient degree of accuracy. More sophisticated approaches may be used and further developed.

\section{Statistical Estimation}

Considering high variation in coral calcification parameters between coral colonies, the estimate of the signal-to-noise ratio can adopt the expressed population signal (EPS) statistic commonly used in tree-ring studies. In other words, we can estimate the signal-to-noise ratio given the number of available samples and mean inter-series correlation coefficient (Wigley et al., 1984). The expressed population signal (EPS) statistic is calculated following:

$E P S=\frac{N \bar{r}}{N \bar{r}(1-\bar{r})} \quad E P S=\frac{N \bar{r}}{N \bar{r}(1-\bar{r})}$

where $N N$ is the number of coral records and $\bar{r} \bar{r}$ is the mean of the inter-series correlation coefficient. In order to reach a signal-to-noise ratio above 0.85 , it is advised to sample at a minimum of about 15 core samples in a study area.

Uncertainty in estimating coral calcification is calculated via an error propagation by accounting for the ranges of coral calcification, extension rate and skeletal density between colonies as well as the intercept and slope errors of the Hounsfielddensity calibration. The last three factors (i.e., inter-colony density range, calibration intercept, and slope errors) contribute to uncertainty 
for skeletal density estimates. The error bars assigned for extension rate is based on the range of estimates between colonies.

\section{CONCLUSION}

This communication presents a relatively simple, practical guidelines from the field to laboratory for assessing coral calcification via three dimensional CT scan as an initial guideline applicable by the WESTPAC's Programme on monitoring the ecological impacts of ocean acidification on coral reef ecosystems.

\section{ACKNOWLEDGEMENT}

A contribution of Riset Prioritas COREMAPCTI 2018 entitled "Rekam Jejak Perubahan Iklim dan Dampaknya terhadap Kalsifikasi Karang" to I.S.N. funded by the World Bank and administered by the Research Center for Oceanography Indonesian Institute of Sciences (LIPI).

\section{REFERENCES}

Bosscher, H. (1993). Computerized tomography and skeletal density of coral skeletons. Coral Reefs, 12, 97-103, doi: 10.1007/ BF00302109.

Cantin, N.E., Cohen, A.L., Karnauskas, K.B., Tarrant, A.M. \& McCorkle, D.C. (2010). Ocean warming slows coral extension in the central Red Sea. Science, 329, 322-325, doi: 10.1126/science. 1190182 .
Dassié, E. et al. (2017). Saving our marine archives.Eos, 98, doi:10.1029/2017EO068159.

Lough, J.M. (2008). Coral calcification from skeletal records revisited. Mar. Ecol. Prog. Ser., 373, 257-264, doi: 10.3354/meps07398.

Lough, J.M. \& Cooper, T.F. (2011). New insights from coral extension band studies in an era of rapid environmental change. EarthSci. Rev., 108, 170-184, doi: 10.1016/j. earscirev.2011.07.001.

Wigley, T. M. L., Briffa, K. R. \& Jones, P.D. (1984). On the average value of correlated time series, with applications in dendroclimatology and hydrometeorology. J. Clim. Appl. Meteorol. 23, 201-213, doi: 10.1175/1520-0450(1984)023<0201:OTAVO $\mathrm{C}>2.0 . \mathrm{CO} ; 2$.

Wong, P.P. et al. (2014). Coastal systems and low-lying areas. In: Climate Change 2014: Impacts, Adaptation, and Vulnerability. Part A: Global and Sectoral Aspects. Contribution of Working Group II to the Fifth Assessment Report of the Intergovernmental Panel on Climate Change (ed. Field, C.B. et al.) 361409, Cambridge University Press. 